Reprod. Nutr. Dévelop., 1986, 26 (2 B), 705-715.

\title{
Digestion des protéines du lait dans la caillette du veau préruminant
}

\author{
Mireille YVON, J.-P. PÉLISSIER (1), P. GUILLOTEAU (*), R. TOULLEC $\left({ }^{*}\right)$ \\ Laboratoire de Biochimie et de Technologie laitières, \\ I.N.R.A., 78350 Jouy-en-Josas, France. \\ (*) Laboratoire du jeune Ruminant, \\ I.N.R.A., 65, rue de St-Brieuc, 35042 Rennes Cedex.
}

Summary. Digestion of milk proteins in the preruminant calf abomasum.

Gastric digestion of milk proteins has been studied in the preruminant calf by analysing gastric effluents in the duodenum after the ingestion of 5 different diets : whole milk, skim milk, casein solution in water, casein solution with minerals, whey.

The amino acid composition of the gastric effluents and HPLC analysis of the latter show that the major part of the whey proteins were evacuated rapidly without any proteolysis and after milk ingestion. On the contrary, all the caseins were largely proteolysed and arrived slowly in the gut. The major part of the peptides obtained came from $\alpha_{\mathrm{s} 1}$ casein. Only a few peptides, principally CMP, were quickly emptied from the stomach.

Dans le monde industrialisé, le lait de vache et les produits laitiers jouent un rôle primordial dans l'alimentation humaine, puisque les protéines du lait constituent de 20 à $30 \%$ du total des protéines alimentaires (Hambraeus, 1982). Cette grande utilisation des protéines du lait est principalement dûe à leur excellente valeur nutritionnelle.

La digestion de ces protéines commence dans l'estomac. Sous l'action des protéases gastriques, la liaison Phe105-Met106 de la caséine $k$ bovine est rapidement hydrolysée (Delfour et al., 1965) entraînant, en présence de calcium, la coagulation des caséines dans l'estomac. L'évacuation de la matière protéique du lait vers l'intestin est donc liée aux propriétés physiques des constituants protéiques (coagulum) et à l'action de l'acide chlorhydrique et des protéases. Le rôle principal de l'estomac est de préparer les aliments à la digestion intestinale et de les évacuer vers l'intestin, après une période de stockage plus ou moins longue.

Dans le but de mieux connaître les différentes phases de la digestion gastrique des protéines du lait de vache, nous avons entrepris d'étudier la nature

(1) Correspondance à : J.-P. Pélissier, Laboratoire de Biochimie et Technologie Laitières, I.N.R.A., 78350 Jouy-en-Josas, France. 
des polypeptides arrivant dans le duodénum proximal après ingestion de repas d'épreuve. Le modèle choisi a été la caillette du jeune veau préruminant qui fonctionne comme l'estomac du monogastrique. Le lait de vache est, par ailleurs, l'aliment qui est naturellement destiné à cet animal. Pour mettre en évidence les effets éventuels de la matière grasse, du lactosérum, des minéraux et de la coagulation, nous avons utilisé 5 régimes différents : lait entier, lait écrémé, lactosérum, solution de caséine en milieu minéral ou dans l'eau.

Les premiers résultats ont montré que l'évacuation gastrique des matières azotées est plus rapide avec le lactosérum qu'avec les 4 autres régimes, confirmant ainsi l'effet retardateur de la coagulation du lait et de la précipitation acide de la caséine (Pélissier et al., 1983). Les analyses électrophorétiques des effluents gastriques ont montré que les caséines sont piégées dans le coagulum ou précipitées et demeurent donc longtemps dans la caillette. Elles ne sont évacuées de la caillette qu'après avoir été transformées en peptides plus petits (Yvon et al., 1984b). Cependant, lorsque les caséines sont ingérées en solution, une petite fraction (environ $15 \%$ ) de la caséine arrive dans le duodénum intacte ou faiblement protéolysée (Yvon et al., 1984a). Par contre, les protéines majeures du lactosérum ( $\alpha$-lactalbumine et $\beta$-lactoglobuline) sont rapidement évacuées sans être sensiblement dégradées. Toutefois, l'acidification de la poche gastrique entraîne environ $3 \mathrm{~h}$ après le repas, la protéolyse de l' $\alpha$-lactalbumine restante $(50 \%$ de celle ingérée). La $\beta$-lactoglobuline n'est pas dégradée lors de son passage dans l'estomac (même comportement électrophorétique pendant les $7 \mathrm{~h}$ ) et arrive dans le duodénum en conservant sa réactivité immunologique (Yvon et al., 1984b).

Les résultats rapportés ici concernent la composition en acides aminés des effluents gastriques, ainsi que l'identification des peptides libérés par analyse en HPLC.

\section{Matériel et méthodes.}

Alimentation. - Les veaux recevaient habituellement un lait de remplacement dont les protéines étaient apportées en totalité par du lait écrémé. La veille des prélèvements le lait distribué le matin, a été additionné de citrate de sodium $(11 \mathrm{~g} / \mathrm{kg})$ pour empêcher la coagulation et accélérer la vidange gastrique (Frantzen et al., 1973). Au repas du soir, les animaux n'ont reçu que de l'eau. Ainsi, lorsqu'ils ont ingéré leur repas d'épreuve, le contenu de leur caillette était réduit au minimum.

Chaque repas d'épreuve était constitué de $5 \mathrm{~kg}$ de l'un des régimes suivants : lait entier $(A)$, lait écrémé $(B)$, solution à $3 \%$ de caséine dans l'eau $(C)$, solution à $3 \%$ de caséine dans un milieu minéral simulant le perméat de lait ultrafiltré (Jenness et Koops, 1962) (D) et lactosérum (E). Tous ces régimes ont été préparés à partir du même lait provenant d'une seule vache homozygote pour les 4 caséines.

Animaux et prélèvements. - Deux veaux préruminants ont été munis d'une canule duodénale réentrante (Ash, 1962). Après chaque repas d'épreuve, les digesta quittant la caillette ont été recueillis en totalité, pendant 20 périodes réparties sur $7 \mathrm{~h}$ consécutives. La durée de chaque période était de $10 \mathrm{~min}$ pendant la première heure, de $15 \mathrm{~min}$ pendant la seconde et de $30 \mathrm{~min}$ pendant les 
5 dernières. Afin de bloquer immédiatement toute réaction enzymatique, les digesta ont été collectés dans une solution d'acide trichloracétique (TCA) dont la concentration finale était de $12 \%$. Le détail des méthodes de collecte et de conservation des échantillons a déjà été décrit (Pélissier et al., 1983 ; Yvon et al., 1984a).

Analyses. - Les compositions en acides aminés ont été déterminées après hydrolyse acide $\left(\mathrm{HCl} 5,7 \mathrm{~N}, 110^{\circ} \mathrm{C}, 24 \mathrm{~h}\right.$, sous vide) selon la méthode de Spackman et al. (1958) à l'aide d'un analyseur Biotronik LC 5000. Les compositions obtenues ont été comparées par analyse multivariate (Hill, 1974).

Les peptides solubles dans la TCA $12 \%$ ont été analysés en HPLC après avoir ajusté le $\mathrm{pH}$ des échantillons à environ 2 avec $\mathrm{NaOH} \mathrm{N}$. La fraction insoluble a été resolubilisée à $\mathrm{pH} 7$ puis précipitée à $\mathrm{pH} 4,6$ pour obtenir les peptides « non caséiques " qui ont été également analysés par HPLC. La chaîne HPLC utilisée était un modèle SP 8700 (Spectra Physics). La détection des composés a été effectuée par mesure de l'absorption à $220 \mathrm{~nm}$ avec un spectrophotomètre Pye Unicam (Philips) relié à un intégrateur SP 4270 (Spectra Physics). L'élution, sur une colonne $\mathrm{C} 18 \mu$ Bondapack (Waters), était réalisée à l'aide d'un gradient linéaire d'acétonitrile contenant $1 \%$ d'acide trifluoroacétique (TFA).

Les peptides isolés de l'effluent gastrique ont été identifiés par analyse de leurs compositions en acides aminés et détermination de leurs séquences Cterminales par action de la carboxypeptidase $A$ (Boehringer) et de leurs séquences $\mathrm{N}$-terminales par dégradation récurrente d'Edman selon la technique décrite par Tarr (1982).

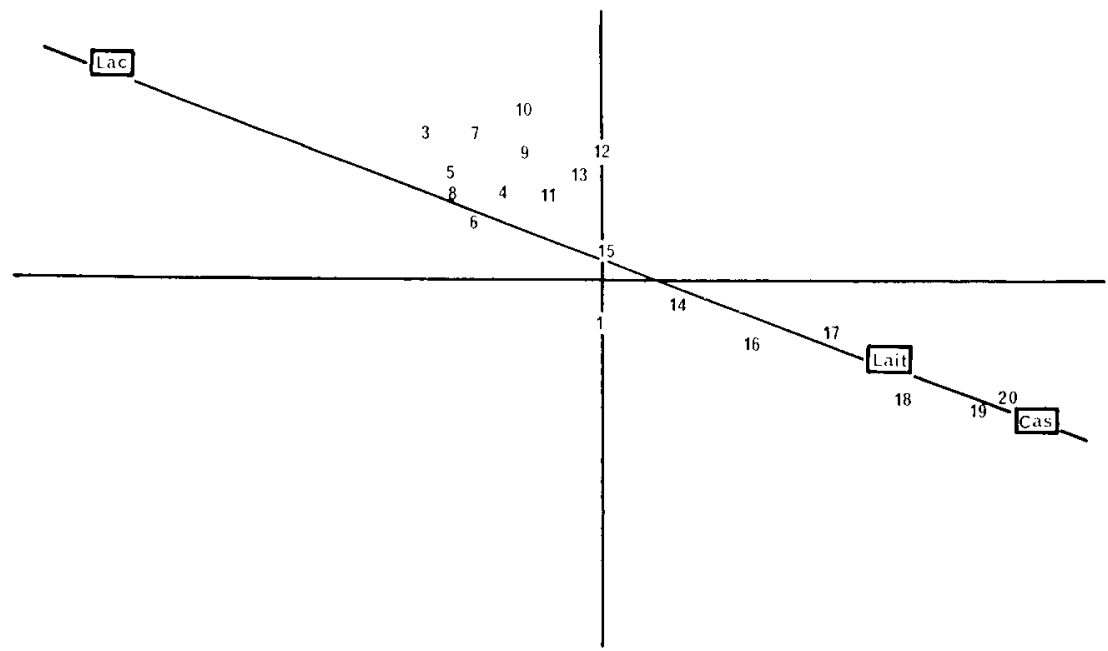

FIG. 1. - Analyse en composantes principales des compositions en acides aminés des effluents gastriques obtenus avec le régime lait, en prenant en compte les teneurs des 17 acides aminés déterminés après hydrolyse acide. (cas) : composition de la caséine ; (lait) : composition du lait ; (lact) : composition du lactosérum ; les chiffres correspondent aux compositions des effluents gastriques obtenus aux différents temps (1) : 0-10 min ; (2) : 10-20 min ; (3):20-30 min ; (4) : $30-40 \mathrm{~min} ;(5)$ : $40-50 \mathrm{~min} ;(6) \quad 50-60 \mathrm{~min} ;(7): 60-75 \mathrm{~min} ;(8): 75-90 \mathrm{~min} ;(9): 90-105 \mathrm{~min}$; (10): 105-120 min ; (11): 2 h-2 h $30 ;(12): 2$ h $30-3 h$ '; (13): 3 h-3 h $30 ;(14): 3$ h $30-4$ h ; (15): 4 h-4 h30; (16): 4 h 30-5 h;(17): 5 h-5 h $30 ;(18): 5$ h 30-6h;(19): 6 h-6 h $30 ;(20): 6$ h $30-$ $7 \mathrm{~h}$. 


\section{Résultats et discussion.}

L'analyse des effluents gastriques par électrophorèse en gel à gradient de porosité en présence de SDS montre que la coagulation du lait entraîne la rétention de la quasi totalité de la caséine ingérée. Ces protéines sont évacuées ultérieurement sous forme de peptides de taille nettement plus réduite (Yvon et al., 1984b).

Les compositions en acides aminés des 2 fractions protéiques du lait (caséine et protéines du sérum) sont très différentes. Après ingestion de lait, la vidange préférentielle de protéines du lactosérum, puis celle des peptides provenant de I'hydrolyse des caséines doivent entraîner, au cours du temps, une évolution de la composition en acides aminés des effluents arrivant dans le duodénum. L'analyse en composantes principales de ces compositions en acides aminés montre qu'effectivement la composition des digesta du régime "lait " évolue entre la composition du lactosérum et celle de la caséine (fig. 1). Dans cette représentation les 3 points correspondant respectivement à la composition en acides aminés du lactosérum, du lait et de la caséine sont alignés. De plus, la position relative du point " lait » sur le segment de droite reliant le point "lactosérum " au point « caséine " est directement fonction de sa teneur en caséine. Nous avons pu ainsi estimer la proportion de caséine (ou de peptides provenant de la caséine) dans chaque prélèvement. Ces résultats sont reportés dans la figure 2 . Dès le premier prélèvement, la teneur en caséine de l'effluent gastrique est très inférieure à celle de l'aliment (coagulation rapide de la caséine). Elle augmente ensuite au cours du temps, en particulier après $3 \mathrm{~h}$ de digestion. Ceci met en évidence l'apparition progressive de peptides provenant de l'hydrolyse des caséines. Après $6 \mathrm{~h}$ de digestion, les peptides évacués sont presque exclusivement d'origine caséique.

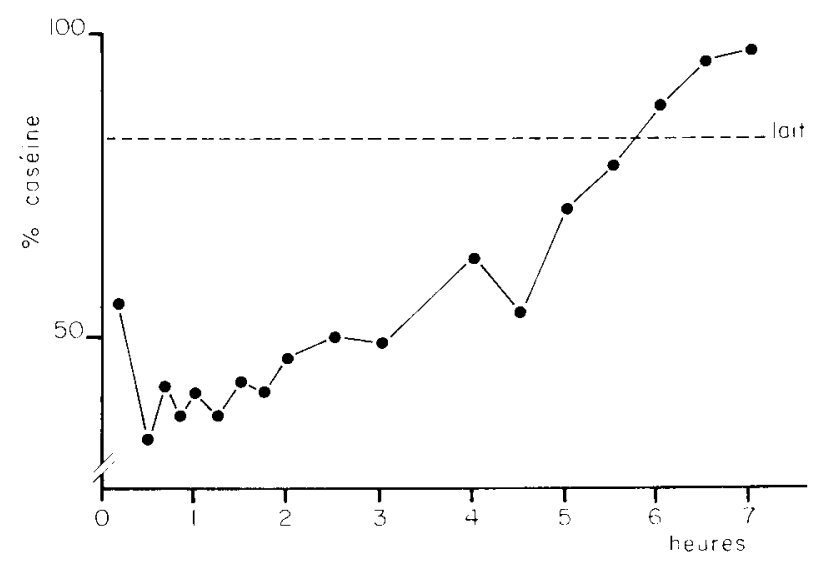

FIG. 2. - Pourcentage de caséine dans l'effluent gastrique estimé après analyse en composante principale des compositions en acides aminés par projection des points sur l'axe reliant la composition du lactosérum à celle de la caséine. 


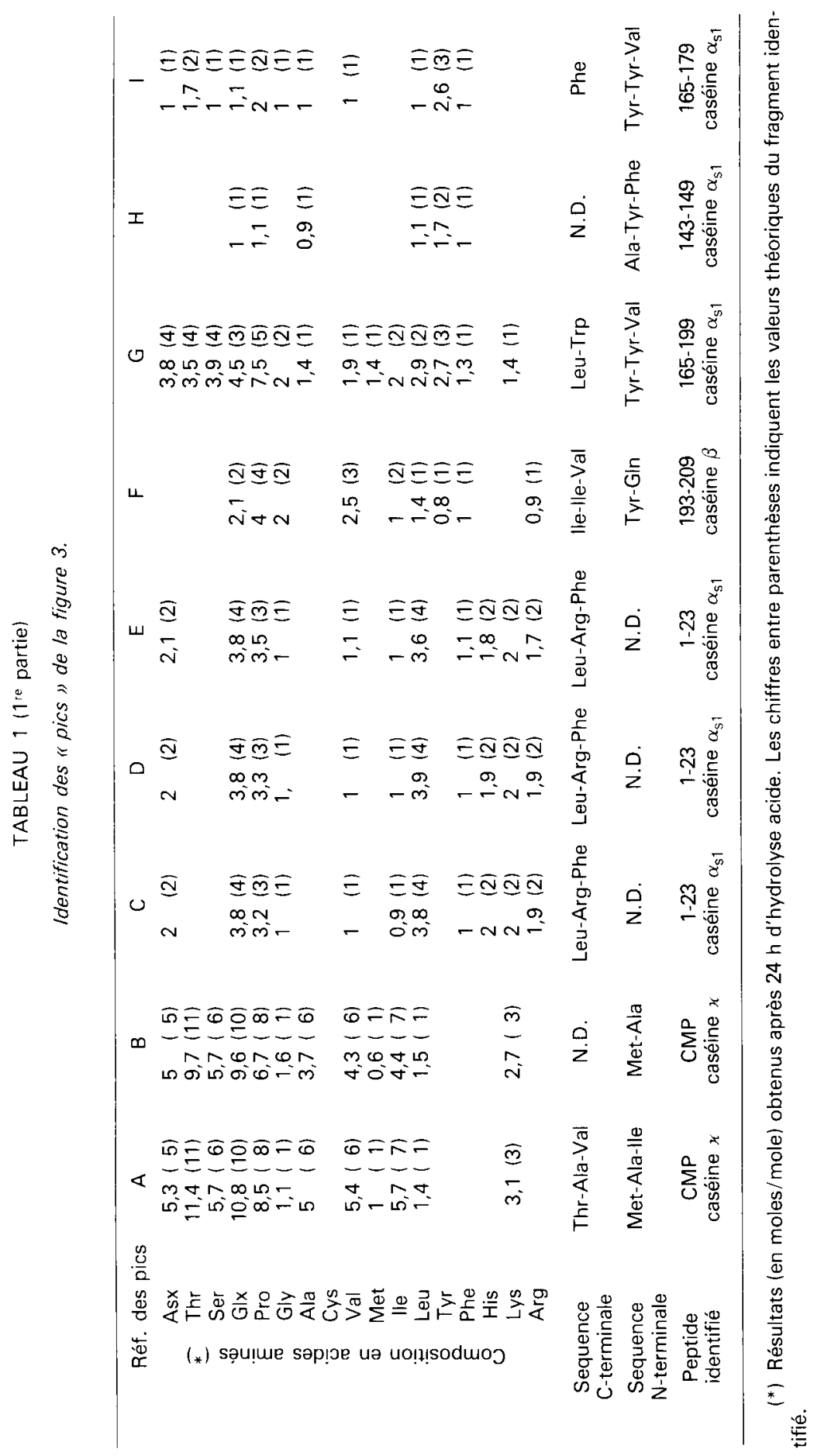




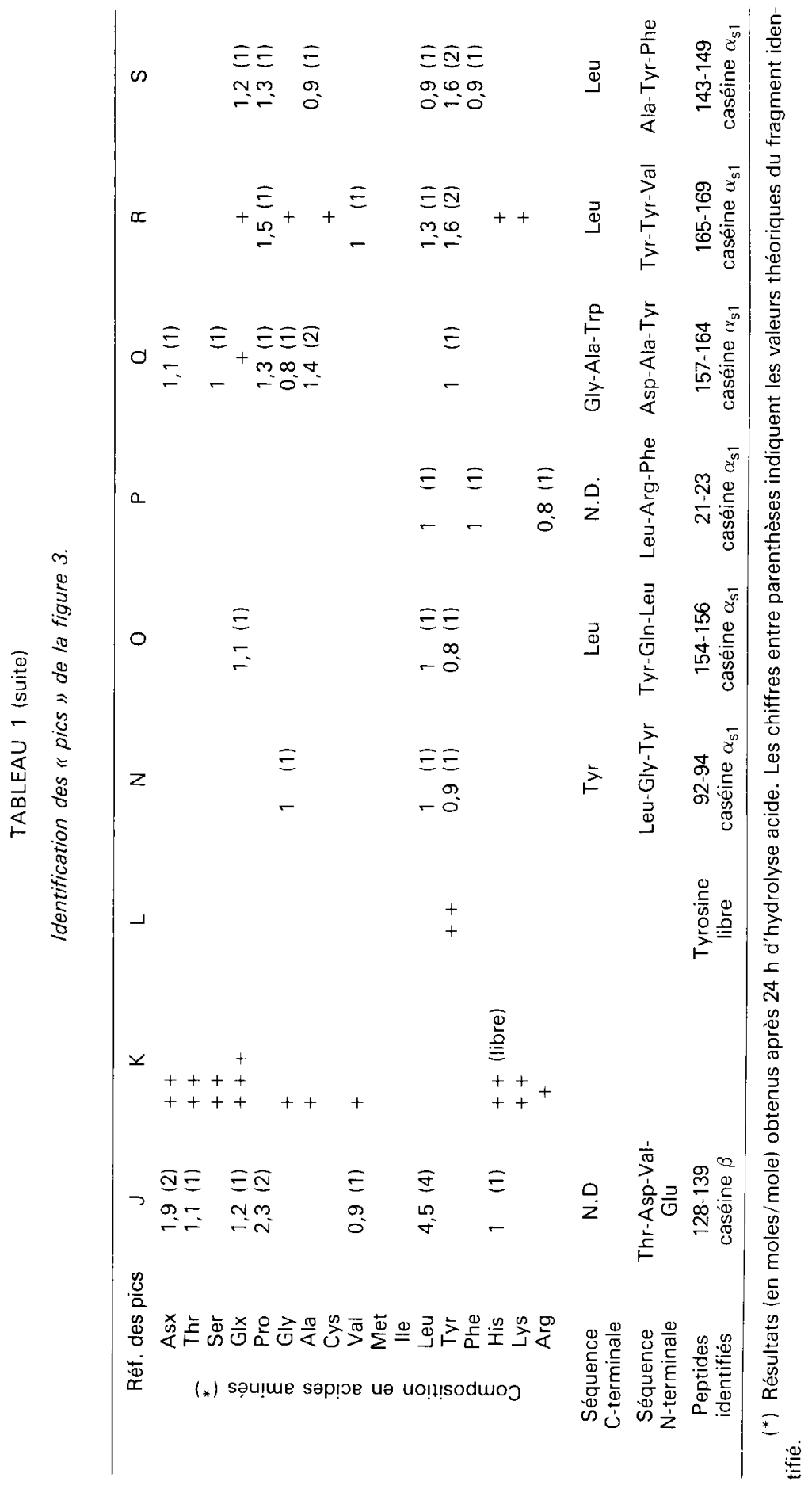


Afin de mieux préciser la nature des peptides arrivant dans le duodénum, les effluents ont été analysés par HPLC en phase inverse. Le nombre et la hauteur des pics s'accroissent au cours du temps (fig. 3). Les principaux peptides ont pu être identifiés (tabl. 1). En se basant sur la hauteur de ces pics, une estimation de la cinétique d'apparition des différents peptides dans le duodénum peut être réalisée (tabl. 2). On constate que certains peptides sont libérés précocément (CMP, séquences 1-23 et 165-199 de la caséine $\alpha_{\mathrm{s} 1}$ ) puis disparaissent de l'effluent tandis que d'autres apparaissent progressivement pendant les $7 \mathrm{~h}$ postprandiales.
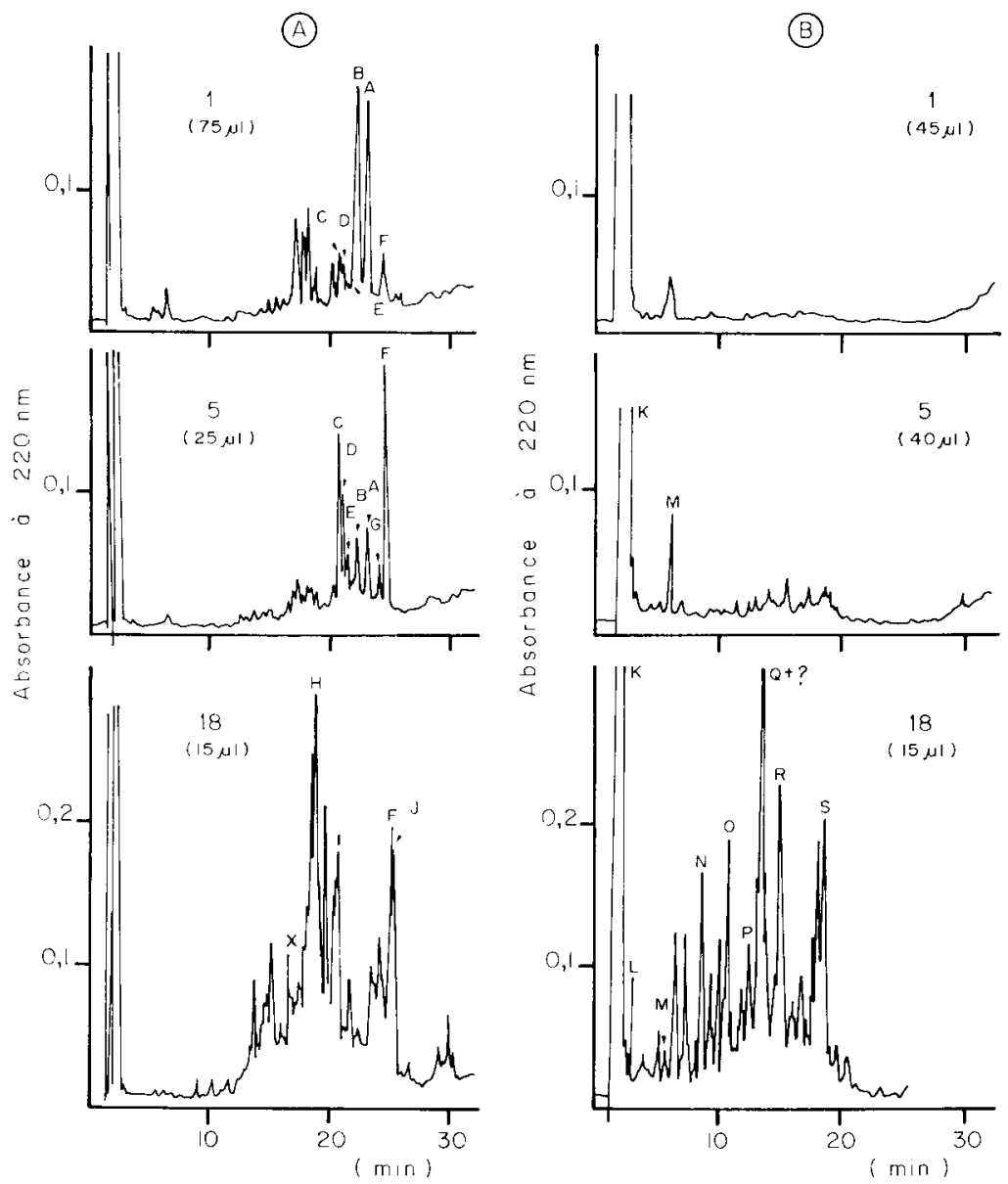

FIG. 3. - Chromatogrammes des digesta recueillis entre $O$ et $10 \mathrm{~min}(1), 40$ et $50 \mathrm{~min}$ (5) et 5 h 30 et $6 h$ (18) après ingestion du repas $C$ (caséine en solution dans l'eau). A : Fraction protéique ; $\mathrm{B}$ : Fraction non protéique.

La cinétique de vidange gastrique des premiers peptides libérés (CMP non glycosylé ou CMPo, peptides 1-23 et 165-199 de la caséine $\alpha_{\mathrm{s} 1}$ et peptide 193-209 de la caséine $\beta$ ) a pu être précisée par dosage quantitatif de chacun d'eux (fig. 4). Pendant la première heure et demie, les principaux peptides quittant la caillette 
TABLEAU 2

Représentation schématique de la cinétique de vidange gastrique des premiers peptides provenant des caséines $\alpha_{51}$, $\beta$ et $\mathrm{K}$.

L'intensité du grisé est proportionnelle à la quantité de chaque peptide présente dans l'effluent gastrique.

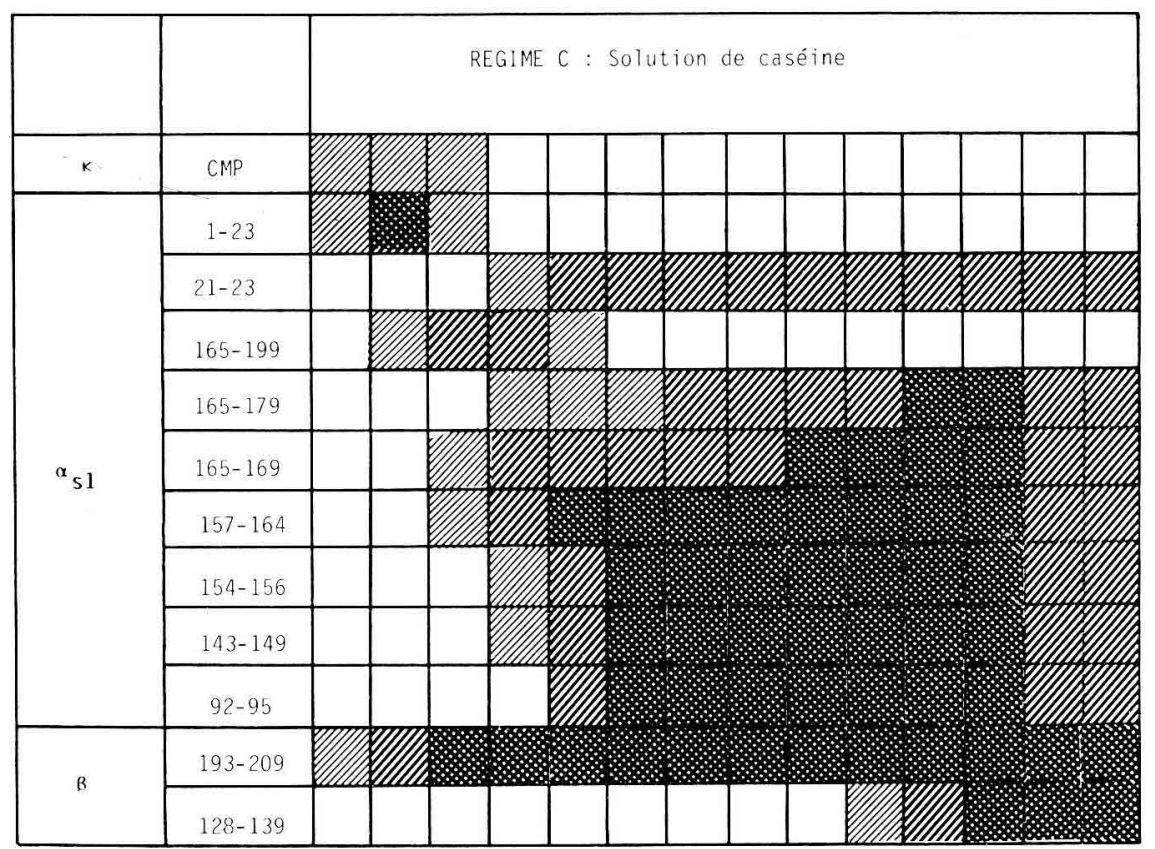

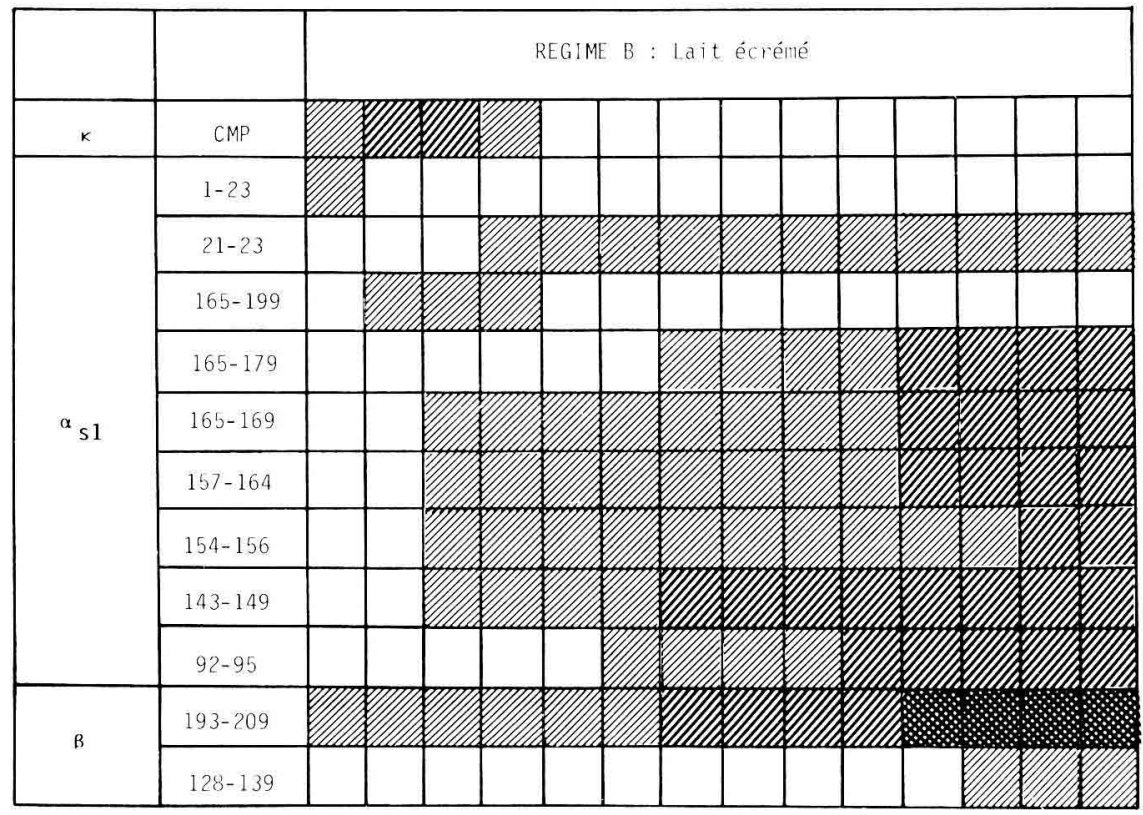




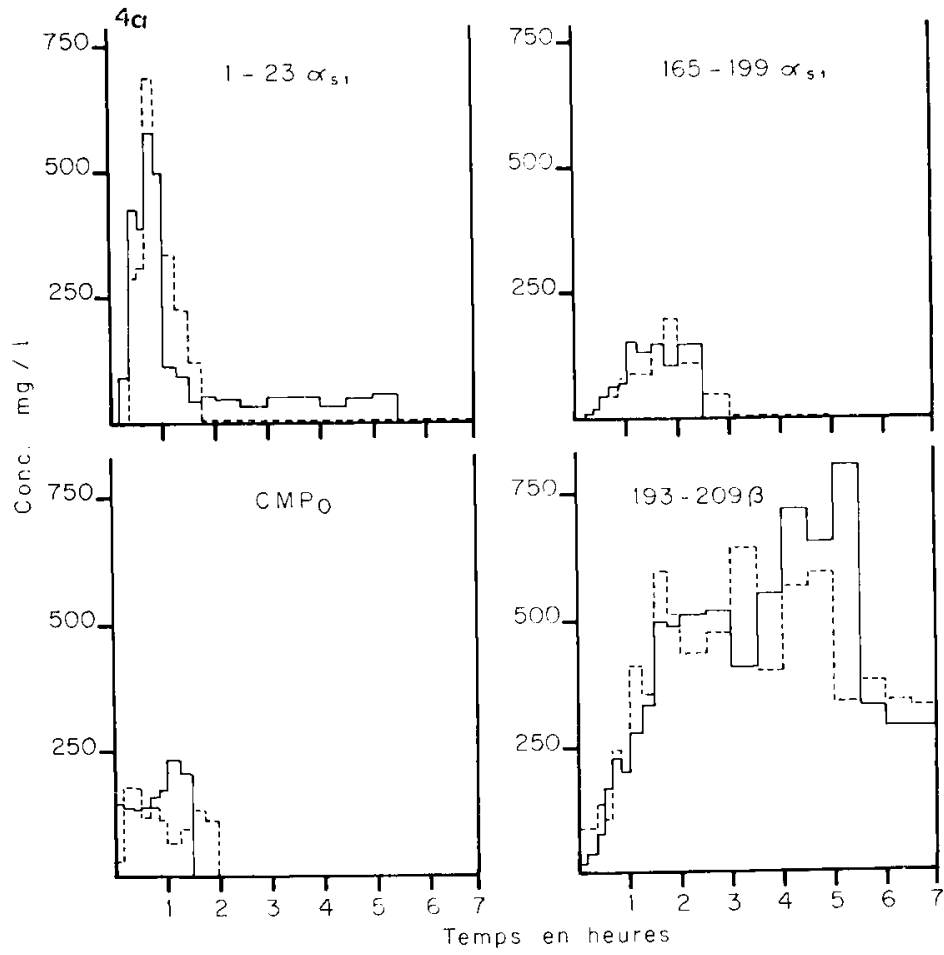

FIG. 4. - Evolution de la concentration des peptides CMPo dela caséine $\mathrm{K}, 1-23$ et 165-199 de la caséine $\alpha_{s 1}$ et 193-209 de la caséine $\beta$ dans les effluents obtenus après ingestion des régimes $C$ $(-)$ et $D \quad(-.-)$ (Fig. 4a) et $B$ (Fig. 4b)

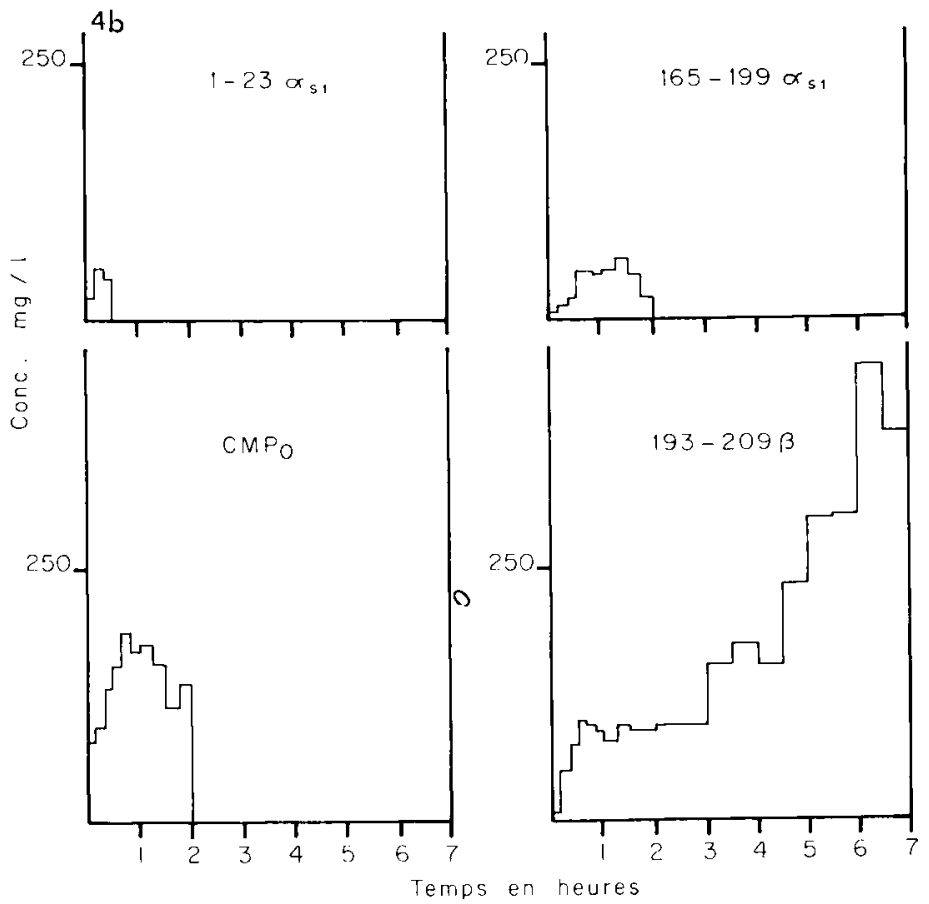


avec les régimes "caséines " ( $C$ et D) sont le CMP (200 à $300 \mathrm{mg}$ de CMPo auquel s'ajoute le CMP glycosylé), le fragment 1-23 de la caséine $\alpha_{\mathrm{s} 1}$ (500 à $600 \mathrm{mg}$ ), le fragment 165-199 de cette même caséine (100 à $150 \mathrm{mg}$ ) et le peptide 193-209 de la caséine $\beta$ (300 à $400 \mathrm{mg})$. Pendant la même période suivant l'ingestion des régimes "lait », une quantité légèrement supérieure de CMP sort de la caillette ( $450 \mathrm{mg}$ de CMPo). Par contre, les quantités évacuées des peptides 1-23 et 165-199 de la caséine $\alpha_{\mathrm{s} 1}$ et du peptide 193-209 de la caséine $\beta$ sont respectivement 10 fois, 2 fois et 2 fois plus faibles qu'avec les régimes " caséine ". Ceci met en évidence la rétention de certains peptides dans l'estomac lors de la coagulation, ce qui a été vérifié in vitro.

\section{Conclusion.}

La digestion gastrique apparaît comme une étape fondamentale de la digestion des protéines du lait. En dehors du phénomène classique de ralentissement de la vidange de la matière azotée par rapport à celle des liquides et des matières solubles, la caillette du veau joue un rôle sélectif sur la nature des protéines et des peptites mis à disposition de l'intestin au cours du temps. Les caséines arrivent dans le duodénum assez lentement et sous une forme très protéolysée. Seuls quelques peptides sont libérés précocement, notamment le CMP auquel certains auteurs ont attribué un rôle antigastrine et un effet inhibiteur sur les protéases gastriques et pancréatiques (Chernikov et al., 1978). En revanche, la majeure partie des protéines du lactosérum arrivent rapidement, sous forme intacte, dans l'intestin. En particulier, la $\beta$-lactoglobuline qui est résistante à l'action des protéases gastriques. Dans nos conditions expérimentales, il n'a pas été possible de mettre en évidence un effet de la matière grasse ou des minéraux sur le devenir des protéines dans la caillette.

La cinétique de digestion gastrique des différents produits azotés du lait apparaît donc comme un phénomène complexe dû au comportement variable des différentes protéines vis-à-vis de la protéolyse et de l'évacuation gastrique.

$11^{e}$ Réunion du groupe Développement I.N.R.A., Montpellier, 22-24 mai 1985

\section{Références}

ASH R. W., 1962. Gastro-intestinal reentrant cannuleas for studies of digestion in sheep. Anim. Prod., 4, 309-312.

CHERNIKOV M. P., STAN G. V., STAN E. Y., SCHLYGIN G. K., VASILEVSKAYA L. S., 1974. Biological significance of caseino-glycopeptide. Vop. Pitan., 2, 21-25.

DELFOUR A., JOLLES J., ALAIS C., JOLLES P., 1965. Caseino-glycopeptides : characterization of methionine residue and of the N-terminal sequence. Biochem. Biophys. Res. Comm., 19. 452-455.

FRANTZEN J. F., TOULLEC R., THIVEND P., MATHIEU C. M., 1973. Influence de la coagulation des protéines sur la vidange stomacale chez le veau préruminant. Ann. Biol. anim. Bioch. biophys., 13, 718-721. 
HAMBRAEUS L., 1982. Nutritional aspects of milk proteins. Chapitre 9. In P. F. FOX, Developments in dairy chemistry, 289-313, Applied Sci. Publ., London and New-York.

HILL M. D., 1974. Correspondance analysis : a neglected multivariate method. Appl. Stat., 23, 340-354.

JENNESS R., KOOPS J., 1962. Preparation and properties of a salt solution which simulates milk ultrafiltrate. Neth. Milk Dairy J., 16, 153-164.

LAURELL C. B., 1966. Quantitative estimation of proteins by electrophoresis in agarose gel containing antibodies. Anal. Biochem., 15, 45-52.

PÉlisSieR J. P., GUILLOTEAU P., BRULE G., TOULLEC R., 1983. Digestion des protéines du lait dans la caillette du veau préruminant. Evacuation gastrique après un repas d'épreuve. Reprod. Nutr. Dévelop., 23, 161-173.

SPACKMAN D. H., STEIN W. H., MOORE S., 1958. Automatic recording apparatus for use in the chromatography of amino acis. Anal. Chem., 30, 1190-1206.

TARR G. E., 1982. Manual Batchwise sequencing methods. Methods in protein sequence analysis. Ed. Marschall Elzinga, 223-232.

TRIEU-CUOT P., GRIPON J. C., 1981. Electrofocusing and twodimensional electrophoresis of bovine caseins. J. Dairy Res., 48, 303-310.

YVON M., PÉLISSIER J.-P., GUILLOTEAU P., TOULLEC R., 1984a. In vivo milk digestion in the calf abomasum. 1. Whole casein digestion. Reprod. Nutr. Dévelop., 24, 587-595.

YVON M., VAN HILLE I., PÉLISSIER J.-P., GUILLOTEAU P., TOULLEC R., 1984b. In vivo milk digestion in the calf abomasum. II. Milk and whey proteolysis. Reprod. Nutr. Dévelop., 24, 835-843. 